\title{
Mäori social work views and practices of rapport building with rangatahi Mäori
}

\section{Hannah Mooney}

Hannah Mooney (Ngäti Raukawa ki te tonga, Te Atiawa, Te Atihaunui a Päpärangi, Ngä Rauru) is a lecturer in Social Work at Massey University in Palmerston North. This article discusses findings from her Masters thesis, completed when she worked for Maori Mental Health Services with rangatahi.

\section{Abstract}

This article presents the results of a qualitative study that explored Mäori social workers' perspectives of working to establish rapport with rangatahi Mäori in community mental health services. The research was conducted using a social constructionist perspective, informed and guided by Mäori-centred research principles. Six Mäori social workers from different parts of the country volunteered to participate in semi-structured interviews. These face-to-face interviews were designed after reviewing current literature and were guided by a practice framework that enabled the voices of the Mäori social workers to be heard, eliciting in detail where their views have come from. The findings from the research showed that Mäori social workers view rapport as essential in their practice and therefore they practise in a way that facilitates this. They utilise values and beliefs in their practice, integrated with a Mäori worldview, that contribute towards rapport building with youth and also with their whänau. Reflective practice is used constantly in order to maintain ethical practice. The practice implications are also discussed; that an understanding of how Mäori social workers view and practise rapport can be beneficial, that there is a need for whänau involvement and that this can enhance rapport with rangatahi, that an inherent valuing of rangatahi is key and finally that reflective practice is essential for Mäori social work professional and personal development.

\section{Introduction}

The health and wellbeing of youth is significant in determining the health and wellbeing of society. The health and wellbeing of rangatahi Mäori is a leading issue as a result of Mäori being over-represented in areas of social, economic and educational disadvantage and because Mäori are a youthful population; the median age of Mäori is 23 years, 13.7 years younger than the total population (Statistics New Zealand, 2010). Mäori social workers engage with rangatahi in many different practice areas and mental health is one of these. Baxter's (2008) Mäori Mental Health Needs Profile reports a high prevalence of mental health needs among young Mäori.

The importance of a therapeutic rapport/relationship and engaging those who access support services has received considerable attention in the literature and is considered a 
key factor needed in order to achieve favourable treatment outcomes (Hawley \& Weisz, 2005; Howgego, Yellowlees, Owen, Meldrum \& Dark, 2003; Norfolk, Birdi \& Walsh, 2007; Thomas, 2007). The aim of this paper is to identify key attributes of Mäori social work that guide the practice of building and maintaining rapport with rangatahi Mäori in the community mental health service setting.

\section{The context of rapport building}

The literature is sourced from a range of areas; it includes other disciplines (i.e. nursing and psychotherapy) and western concepts of rapport building and is also more specific, social work, youth and Mäori focused. Considered first is whether rapport is necessary and beneficial and following this is a section on how rapport is established.

\section{The importance of rapport}

A therapeutic relationship is not easily measured and difficult to promote as evidence based, therefore it does not get enough credit in how it benefits clients (Thomas, 2007). However, there are studies that show that a therapeutic alliance/rapport/relationship between a helping practitioner and a client is more likely to indicate improved patient satisfaction, symptom improvement (Hawley \& Weisz, 2005; Norfolk et al., 2007) and better health outcomes (Howgego et al., 2003; Norfolk et al., 2007). Antoniou and Blom (2006) argue that it is the quality of the relationship that will decide how effective the therapy is, not the therapy alone. Clients also report that they want genuine and meaningful interaction with those in helping roles (Cram, Smith \& Johnstone, 2003; Maidment, 2006; Ware, Tugenberg \& Dickey, 2004). Rapport is essential when working with Mäori and whakamä (shyness, embarrassment) decreases as a rapport relationship is built (Cram et al., 2003). Hirini (1997) asserts that a clinician should not ask or expect a Mäori client to share personal information without firstly taking time to establish and develop trust and rapport.

The absence of a therapeutic relationship means that the young person is likely to end treatment, experience dissatisfaction (Garcia \& Weisz, 2002) and as a result treatment resistance increases (Bickman, et al., 2004; Garcia \& Weisz, 2002). It is also strongly suggested that rapport serves as a protective factor against suicide (Ministry of Health (MOH) \& New Zealand Guidelines Group (NZGG), 2003) and assists clients to develop alternative methods of coping (Nafisi \& Stanley, 2007). The relationship, according to participants in O'Brien's (2001) research, also meant fewer hospital admissions.

\section{How to establish rapport}

Ruwhiu and Ruwhiu (2005) assert that social workers need to achieve peace within the self before being able to recognise peace within practice. As a clinician, this knowledge of self is imperative but the 'use of self', in order to establish rapport with clients, is debated. The use of self-disclosure to build rapport is a contentious issue with some researchers arguing that this should be done (Sterlin, 2006), while others believe that it should be used sparingly and with caution (Cahill, et al., 2008) or only used when the intention, content and purpose is ethical and clear (Bogo, 2006). A part of this knowledge of self is having knowledge of one's own whakapapa (ancestral links). The sharing of this can help the client to feel more comfortable and settled because of the connections that can be made. In the Mäori world the communication of whakapapa is accepted as a cultural norm. It is the beginning of whakawhanaungatanga, the process of establishing and actively developing relationships (Ruwhiu, 2001). 
A recurring theme in the literature is that relationships need to be clearly defined, including the boundaries, the purpose and the goals (Cahill et al., 2008; DiGiuseppe, Linscott \& Jilton, 1996; McLean, 2007; O'Brien, 1999; O'Brien, 2001; Reid \& Fielding, 2007; Shattell, Starr \& Thomas, 2007). English, Selby and Bell (2011) interviewed Mäori 'social workers in schools' (SWiS) and found that kaupapa and tikanga supported them to make the right decision/s in practice.

Diverse Mäori realities need be taken into account, for both the social worker and the rangatahi because there is no single cultural reality for Mäori (M. Durie, 2001). Despite this, Walsh-Tapiata, et al.'s (2006) participatory action research, involving rangatahi as both researchers and participants, identified that no matter what level of cultural understanding the young person has, the practice of cultural processes still contributed to a solid sense of distinctiveness and cultural identity. Wellbeing for Mäori is synonymous with having a positive cultural identity (M. Durie, 2001; Huriwai, Robertson, Armstrong, Kingi \& Huata, 2001; Kingi, 2005).

It is therefore essential to become competent in the use of Mäori tools of engagement such as te reo Mäori (Mäori language), karakia (prayer), whakapapa, pükörero and moemoeä (stories and aspirations), because these are the vehicles to a cultural and spiritual practice framework, that in turn allow for deeper relationships to form between client and worker (Ruwhiu \& Ruwhiu, 2005). When Mäori are working with Mäori, clinicians need to have confidence in their intuition and have an acute awareness of the working environment and body language (Jonson, Su'a \& Crichton-Hill, 1997). The SWiS, in the study by English et al. (2011), practise in a way that involves expressing affection in a culturally appropriate way through physical touch (such as a hug or a kiss).

Walsh-Tapiata et al. (2006) accentuated the need for a relationship of trust between adults and youth. McCutcheon, Chanen, Fraser, Drew and Brewer (2007) recommend that to engage with a young person, a non-blaming approach needs to be taken. Their tips and strategies on how to build rapport with a young person are to be yourself, be clear, open and honest, and to use metaphor and humour.

These views are supported by research on what clients want from a helping professional; the use of touch, compassion, love, reciprocity, spiritual engagement and to be able to tell their story (Maidment, 2006). Clients want kindness, warmth, a non-judgmental approach, responsiveness, accessibility, respectfulness and a knowledgeable social worker (Beresford, Croft \& Adshead, 2008). Mäori social workers are led by what Ruwhiu (1995) and A. Durie (2001) term a ngäkau Mäori (a Mäori heart), personal qualities of empathy, warmth and compassion. Duncan, Miller and Sparks (2004) promote a client-directed practice approach where successful treatment is the result of a positive therapeutic alliance and the tailoring of the treatment approach to the client and their understanding of the problem.

\section{Research design}

The purpose of this research was to elicit how Mäori social workers view and practise rapport building with rangatahi Mäori in community mental health services. The design for this research was built on a postmodern, social constructionist theoretical framework (Berger \& Luckmann, 1971). The elements and values involved in building and establishing rapport were viewed as 
socially constructed. This meant that there was recognition of the process by which different perspectives are shared and organised through social interaction and activity, resulting in shared social understandings and behaviours (Berger \& Luckmann, 1971). Qualitative research complemented this position because it seeks to answer questions about social processes, understandings and belief systems (Barbour, 2008). It investigates social settings, the individuals within these settings, and how the individual makes sense of the social setting (Berg, 2007).

Mäori-centred research principles guided the research and the interview process (A. Durie, 2001). The Massey University Human Ethics Application was completed. The literature review and the Integrated Practice Framework (Keen, 2005; Nash, Munford, \& O’ Donoghue, 2005) informed the interview questions and thematic analysis was utilised to construct themes (Braun \& Clarke, 2006). This methodology suited the researcher, as a Mäori/Päkehä social worker working in the area of rangatahi Mäori mental health.

A Mäori-centred research framework locates Mäori as significant participants and Mäori as the researcher/s (Cunningham, 1998). This approach was chosen because Mäori-centred research asserts a Mäori philosophy and caters for the contemporary realities of Mäori (A. Durie, 2001). Mead's (1996) ethical principles for research with Mäori were applied: Aroha ki te tangata (a respect for people), Kanohi kitea (presenting yourself face-to-face), Titiro, whakarongo ... körero (look, listen ... speak), Manaaki ki te tangata (share and host people, be generous), Kia tupato (be cautious), Kaua e takahia te mana o te tangata (do not trample over the mana of people) and Kaua e mähaki (don't flaunt your knowledge).

The Integrated Practice Framework 'aims to promote informed and intentional social work practice and is a means through which the practitioner can describe ... evaluate and justify their assessment of and intervention with clients' (Nash et al., 2005, p. 24). It encourages a process of action-reflection to occur where social workers reflect on their practice; effectiveness is evaluated, and changes made as a result (Nash et al., 2005). A simplified version of the Integrated Practice Framework is illustrated:

Practitioner as person

Practitioner as theorist

Practitioner in practice

ongoing process of action-reflection

Practitioner as person relates to what the person brings to their social work role; their world views, values, beliefs, ideals and dreams. It is heavily influenced by how the social worker was raised, and their experiences in life, including their prejudices. Practitioner as theorist is about how the social worker views the world from a theoretical standpoint, in general and from a social work perspective. Practitioner in practice is how both practitioner as person and practitioner as theorist combine at a practice level with the client. The process of actionreflection is where the social worker consistently reflects on his or her actions, the thoughts and feelings connected to the actions, and what has informed these actions. This is where personal and theoretical views are explored in relation to how they may interrelate and affect practice decisions and interactions.

\section{Criteria for participants}

The criteria for the research participants was that: the participants needed to self identify as Mäori, to have a social work qualification (diploma or degree), to be working in the mental 
health field in the community with rangatahi Mäori, to be employed as a social worker and to reside or work in the lower North Island (this final criteria was extended to nationwide in order to access a wider pool of participants). The aim was for at least two participants to be male, however only one male opted in. This sampling technique is non-random volunteer sampling (O'Leary, 2004). This is an appropriate form of sampling for this research because the criteria are specific. Six Mäori social workers were recruited through advertisement, email networking and word of mouth. The wisdom and knowledge shared by these social workers was based on 18 months to 12 years of professional social work practice as well as their life experiences. Two of the participants were $30-40$ years of age and the other four were aged between 40 and 50 years.

\section{Semi-structured interviews}

The semi-structured interview was chosen to create an environment of flexibility in the interview itself, while also allowing the interview to remain focused on the topic area. Questions could be adjusted in order to elicit further information (Berg, 2007). A pilot interview was carried out to trial the interview process and was included in the research. Piloting helps ensure that the questions obtain the data required and tests the progression of the interview (Barbour, 2008). In alignment with Mäori-centred research and the research topic they were completed face-to-face with key considerations being the provision of time and attention to process. A dictaphone was used to avoid the distraction of note-taking, therefore enabling full focus on the interview and interview process. Tikanga (Mäori custom) processes were undertaken with karakia (prayer) to open and close the interview, a strong focus on whanaungatanga (making connections and relationship/rapport building) and kai (food) was provided and shared at the conclusion of the interview.

\section{Thematic analysis}

A common form of analysis involves summarising themes that are common in the transcripts and providing quotations to support the argument (Abell \& Myers, 2008). Thematic analysis is a method of identifying and reporting patterns or themes out of the interview data and was drawn from both the literature and the research. When a theme is identified across the interviews it can then be said that the idea is shared across a wider group, rather than just at individual level, and therefore can be put forward with more assurance (Denscombe, 1998). Themes are formed using both inductive and deductive approaches; themes identified from the interviews were compared to those already established from the literature review. The aim of the process of theme generation is to move from raw data to data that is more meaningful (Denscombe, 1998; O'Leary, 2004).

\section{Results}

This section is divided into four main themes as generated from the interviews by thematic analysis. Theme one explores whether participants value rapport in their practice and their thoughts/perspectives on rapport. Theme two is about the worldview of the social worker and what it is that informs their thoughts, perspectives and practices of rapport. Theme three asks the question, how do you know when rapport is established? Theme four explores the process of action-reflection and boundaries.

\section{The importance of rapport}

Mäori social workers described rapport as an element in their practice that is very important. Without rapport their work is either very difficult or unable to proceed because rangatahi 
Mäori may not engage with them or the service and may base future contact with services on their previous experiences. There was a definite emphasis on building rapport as early as possible.

It's those first meetings that are make or break times...if you don't begin building a good rapport ... chances are you won't see them again.

... [without rapport] they're not gonna open up, they're not gonna trust you, and they basically won't come back to you either.

... building rapport builds in trust ... without rapport or without engagement you can't actually do the rest of the work.

This has an impact on access to treatment and can continue to contribute to poor mental health outcomes for Mäori as they will often return to services in a more deteriorated mental state.

... the young person doesn't get treatment or they end up coming back to the service in a worse state.

Crisis work was viewed as a priority, however, did not exclude the need for rapport because it established the trust needed to facilitate genuine commitment from the young person to participate in safety planning. Participants therefore connected rapport with more positive treatment outcomes.

Generally [the presence of rapport] creates positive outcomes, pretty much all of the time.

[When rapport is developed] the quicker you get the desired outcome, simply because it's an easier process in every aspect.

In addition, the social workers also talked about the need for role definition and kaupapa to guide the rapport. The kaupapa, or purpose for being there, was seen as essential ... without the kaupapa, the rapport is meaningless. In this, process precedes task, to be asking someone to look at behaviour changes, or to look at doing specific tasks, it's very difficult if you don't have that rapport.

It can be established that from the participants' perspectives that rapport is an integral practice for them based on their professional experience of working as social workers, working within the field of mental health and working with rangatahi Mäori. Other values and beliefs also play a role in where this value comes from, which leads into theme two, the worldview of the Mäori social worker and how this relates to how they work to establish rapport.

\section{The worldview of the Mäori social worker and how to establish rapport}

It is acknowledged that we all have our own unique worldview; however a number of themes came through in the interviews that led to the following key areas being identified as being, arguably, a Mäori social work worldview.

\section{Use of self}

A general consensus among the participants is that it is important to be yourself and be comfortable in your own skin whilst still maintaining professional practice. The participants 
identified specific influences from their upbringing, their values, their culture, being Mäori, being male or female and so on. They utilised these aspects of themselves to connect with Mäori youth and also with their whänau.

... being a Christian has been useful when I've gone into homes where other people have identified as being Christian.

... being a female and being a mother, and having empathy and being nurturing ... I notice the women my mother's age and Mäori women, just the way they talk to others and ... make the process very smooth for themselves in building relationships with people, that is just a natural thing that goes on.

All of the Mäori social workers defined their role as that of social work professional, but a majority also identified with familial roles and characteristics, such as mother or aunty, within their practice. This practice enabled the social workers to connect as Mäori, as whänau and to connect at a wairua (spiritual) level, but created ethical and boundary tensions that needed ongoing and careful consideration (this links in with the theme on reflective practice).

I just kind of bring a mother or an aunty thing, so if my client's unwell, I'll just treat them as if they're my child.

I've always sort of had this aunty way about me.

The social workers utilised touch, awhi (embrace), music, waiata (song), spiritual connection and genuine nurturing. These are used in day-to-day practice and also to de-escalate critical situations. With these values and tools of practice the social workers were able to connect with the rangatahi on a different level and provide a calming environment.

I was rubbing her arm and I just started singing a waiata and it was really good, it de-escalated the situation.

... we'll go to the local marae, or we would go along the beach and talk about Tangaroa and the relationship to how that person's feeling.

They are informed by Mäori values of whanaungatanga, aroha and manaakitanga which are about fostering relationships, a genuine care and love for people and treating others as you would like to be treated.

\section{Treat others as you would like to be treated}

The social workers identified a real value for fellow human beings and this has led to a genuine empathy in practice and a desire to treat others with empathy and respect. For one participant this was informed by personal experiences in dealing with services themselves with their own family.

... with having my own family that have been through the mental health system ... teaches you to have more than awareness, more empathy ... I saw that's not the way to do it ... don't treat people like that, treat them the way you'd like to be treated.

...people can tell ... when you're being honest and you're genuine and you truly can empathise with their situation.

The Mäori social workers identified that being clear and straight-up in practice helps to facilitate rapport building with rangatahi and their whänau. This fits with the idea that kaupapa and tikanga processes are key to defining the boundaries of the relationship. It 
also continues to solidify a relationship of respect.

I've actually had to ... tell them hard truths and things that they haven't wanted to hear...then later [they] will say to you, well actually I needed to hear that ... it actually helps in the long run.

I think being straight-up to Mäori whänau is the best thing that you can be.

... you've got to be really clear what you are prepared to offer and stick to it.

... it's not about friends, it's not about like/dislike ... you've gotta job to do at the end of the day.

... to show role, purpose, boundary. It just naturally comes into play and people feel more secure...you should always when you're working with complex families come back to your role and purpose all the time, and talk about that, because that keeps you safe.

This practice was acknowledged as particularly important when working with rangatahi. According to these Mäori social workers, rangatahi appreciate this approach, even if there is some resistance at the beginning. A straight-up approach means they know where they stand, that you are being genuine, open and honest, without a hidden agenda. The Mäori social workers also stated that there was a high likelihood of seeing the rangatahi and/or their whänau in the community outside of work hours. This is mainly due to the connections between whänau, hapü and iwi in the area.

You're not meant to take clients in your private car, but after work hours if I see my client with a whole lot of shopping walking home and we're both going that way ... we are much more likely to see people outside of hours and interact with them.

I've worked with rangatahi who live in the same area as me, and I've made it really clear 'I don't expect you to turn up on the doorstep' ... I had a situation where a young person ... turned up on my doorstep at night, and so I just said 'well we need to ring your mum'.

While this may appear contradictory with the importance placed on the provision of time and process, the participants were adamant that these two practices can co-exist and both work to facilitate rapport.

\section{Time and process}

The social workers shared how important time and process was to establishing and building rapport with the rangatahi and also with their whänau. This included being humble, respectful, flexible, allowing process to occur and complete even if it extended beyond the social worker's paid hours of employment. This is demonstrative of a genuine commitment to the young person and the family, for example in a crisis situation the social worker is reliably there with them through the whole process.

She didn't get into hospital until 9.30 at night. The family had seen me sit with them all afternoon actually and they were really, really grateful.

I think one thing that Mäori don't like and I don't care how pulled away they are from our culture, they don't like people just getting into it and that's a lot what happens in mental health 'cause we're time poor and stressed out.

... it's okay if we' re a little bit late or a little bit early, or go over time, I don't stress about time

... sometimes an hour doesn't do it.

The provision of time shows the rangatahi that they are important, that the social worker wants to listen to them, and that the social worker is accessible and available. It reinforces a 
genuine practice and a trust relationship. It acknowledges them as individual people with unique experiences and therefore helps to facilitate rapport building.

... people can't be rushed especially rangatahi, 'cause they're always rushed, this is the world of being rushed ... fast food, everything. And I think it's about the fact that rangatahi need a lot more time to know that they can trust you.

The authenticity of the Mäori social worker is fed by an inherent value of people, of families, of rangatahi, of Mäori.

\section{Valuing rangatahi Mäori}

The Mäori social workers talked about valuing the rangatahi, viewing them as a taonga (treasure) and important because they are the future. This demonstrates a respect for rangatahi that directly influences the energy and effort that is put into developing and maintaining rapport with them. It involves remembering what it was like to be a teenager and how that might have changed today with the different pressures, as well as having knowledge of adolescent developmental traits and needs. Participants felt that this understanding made it easier for them to relate to and work with rangatahi and it also meant a level of flexibility required in their practice.

... they're resilient ... they have to combat so many things and they bounce back so quickly from it.

I think rangatahi are all very strong ... they carry around ... traits of their tüpuna.

I think a lot of our rangatahi have respect ... they have a generosity of self ... they really want to be good and to be liked, and I guess we all want that and to feel valued.

I've learnt a lot from them ... they'll tell you how it is ... It's one way they build rapport...that whänau concept of I wouldn't have the knowledge without them, they wouldn't have the knowledge without me.

... a lot of workers are offended by clothing, they're offended by language, they're offended

by stature ... I don't have a problem with that, that's part of them.

... there was a lot of stereotyping and it was the total opposite, the youth had the complete respect for the place.

An important factor when building relationships with rangatahi is to consider the work environment. The participants spoke about spending more social time with the rangatahi, providing kai, going for walks and using metaphor, music and visual aids. Mäori social workers see the need for flexibility in practice when working with rangatahi. These activities tend to integrate things Mäori.

... if they want to listen to music every time that's okay, because eventually they get sick and tired of doing it, and well I find, they decide 'well I might as well talk to you then'.

I'm lucky enough to be able to just cruise down the road with them to the hoops and take a ball down and throw hoops.

I like to have candles, scents, atmosphere, position the room right, have things that are Mäori there in the room, they all help.

... like a kid that's coming in to see you after school, what's the first thing a kid does when they get home after school? Straight to the fridge, so if they're having to come to your office, you show them the fridge.

I like a laugh, so I often use humour. Often use music, and for those that refuse to talk, I often use art and the whiteboard, and lots of metaphors. 


\section{Integrating Mäori knowledge}

The social workers reported that it is essential to understand Aotearoa New Zealand history and how it impacts on the present day. A social work role is then to educate and assist rangatahi with their cultural journey as many have been disconnected from knowledge of their whakapapa. This is not a difficult task given that the Mäori social workers identified that this is their lived reality and a journey that they have undertaken, therefore identifying with the young people, for example, walking in two worlds and being a child from a bicultural background and how to manage this.

... a lot of the kids today are actually quite confused about our history and their culture and being able to actually share some of your knowledge in that area actually assists them big time ... Some of them will come to me just for those little sessions ... and that is a really big part of the rapport ... it really helps in where they're going, in their journeys.

All of the social workers interviewed reported following practice frameworks that originate from Mäori philosophy and theory. They are practice frameworks mainly utilised in the health domain. The sharing of whakapapa was identified by the social workers as a way of making connections and therefore building rapport.

With the Mäori families it's a given that you go and shake their hand and you either hongi or you kiss them ... talking about your whakapapa it's essential to do that with their whänau.

... if you know whakapapa you can ... talk about their marae and talk about their whänau ... and that's why whanaungatanga is so brilliant in its concept ... you're doing karakia, mihimihi, you're talking about the issues just like on the marae.

... when you see a client ... I always see who's behind them ... their tipüna, who they really are ... and I always keep in mind, this person is not just their illness.

While diverse Mäori realities were acknowledged, the Mäori social workers insisted on using te reo Mäori, karakia and other cultural practices. They incorporate te reo Mäori into their day-to-day engagement with rangatahi and whänau by greeting them and farewelling them in te reo Mäori. They assert that this practice honours their culture and identity and, as a consequence, builds rapport.

... using te reo, kia ora, even if they never say kia ora to you or even if they're so urbanised, removed, disenfranchised, colonised ... [I] still use it. There's an inherent thing in us as people, resounds within us and our wairua knows and hears it and responds to it. So I always say kia ora and I always say ka kite and use basic words, but not in a way to make them feel stink, but in a way that honours them being Mäori.

\section{Whänau involvement}

The Mäori social workers identified that a good relationship with the whänau (more often than not) actually created a stronger relationship with the young person. They reported that not only was it safer and more practical to have family involvement, it assisted in establishing and maintaining rapport in most cases.

... because then this young person sees that I am really okay with the family, well she is also really okay with me.

You bring in whänau ... and they can see that the whänau are there to support them.

... after hours family members have rung the mental health line for help but they say 'no we want to talk to [the social worker]' ... that's because of the trust that we've been building and working with. 


\section{Reciprocity - How do you know when rapport is established?}

The concept of reciprocity as an element of rapport building was identified by these Mäori social workers. When the young person and the family know that the social worker is genuine and/or has made allowances above and beyond then they will reciprocate the input into the relationship. The rangatahi and their whänau will respond in a way that is more proactive, accessible, do more for themselves and have more respect for the social worker and their role in the process.

... if you respect somebody and you have that tika, pono and aroha and you really respect and manaaki people, you only get good things back in return.

I went an extra mile and now they will go an extra mile, so when I ring them they will get back because they feel obligated.

... things like turning up ... being at home when they say they're going to be there when you're visiting.

... they will bring their siblings with them, or their friends who also have issues. And so they trust me with their friends and their family.

\section{Boundaries and reflective practice}

All of the social workers maintained that reflective practice is vital in regards to keeping themselves, their organisation and their clients safe. They explained that although rapport is very important, there are times when boundary and ethical issues arise. Good supervision and the practice of internal reflective processes were seen as essential, described as a given, that it occurs constantly and that it is part of being a social worker. Many highlighted the importance of a variety of supervision options, for example having both clinical supervision and cultural supervision.

... you have to be reflective ... constantly trying to seek more knowledge about improving your awareness of what you're doing.

... is this the best way to work with the family, going back to the family is this working for you?

It's always thinking about how your words will land on people ... how much is appropriate to give and how much is damaging to give.

This includes awareness of roles and whether the social worker is the right person to work with the rangatahi.

What's my role? What have I brought to this? It occurs constantly 'cause you're always questioning why you do things.

I'm not the best person to work with them ... there's this young man who thinks he's a rock star and is the son of a famous musician ... he doesn't need 'Aunty' he'd be good with one of our clinicians who's ... in a band himself, so we all bring what we bring.

\section{Practice implications}

Overall this research provides awareness and understanding into what informs and drives the practice of Mäori social workers who work with rangatahi Mäori. This research provides insight into Mäori social work thinking and practices and the purpose of these. What is suggested from the literature and the outcomes of this research is that organisations need 
to be aware of how valuable a rapport relationship can be (particularly for Mäori social workers and the individuals and families they work with) and the resources, time and space required in order to achieve this. While this can be difficult due to the likelihood of there being a lack of resources, and time and space may be seen as a luxury when certain tasks are required, for example crisis/high risk assessments, these interactions are enhanced and more authentic with rapport. Following are some key discussion points that explore the topic and the practice implications of each. This information may be helpful for new Mäori social work practitioners starting out in this field. It may also give fresh insight to non-Mäori social workers working alongside as colleagues and also to those who work with rangatahi Mäori. In addition it will assist to increase the understanding of service managers who assert the organisational boundaries and support their staff.

\section{An understanding of how Mäori social workers view and practise rapport}

The Mäori social workers concurred with the research and rapport was rated very highly and reported to be an essential component, needed first and foremost, connected with positive treatment outcomes (Hawley \& Weisz, 2005; Howgego et al., 2003; Norfolk et al., 2007) and crisis intervention (Nafisi \& Stanley, 2007; MOH \& NZGG, 2003). They supported that rapport needed to occur early in the relationship if not during the first couple of sessions, recognising that a failure to do so can create problems for the young person later on, either with future relationships or with access to treatment. They purport that without rapport access to treatment and/or the appropriate treatment can be severely compromised (Bickman et al., 2004; Garcia \& Weisz, 2002).

However, rapport alone was not seen as ideal and there needed to be a kaupapa (purpose) to guide the interaction. The Mäori social workers spoke about the need for a clear kaupapa, for clear tikanga processes, whanaungatanga principles and Mäori models of practice to drive the boundary setting right from the outset and believed that this left little room for misunderstandings to occur. They reported that they are clear and straight-up from the beginning and open and transparent with the rangatahi and their whänau about boundaries, roles and responsibilities. This aligns with the research that insists on a need for clear role and boundary definition (Cahill et al., 2008; DiGiuseppe et al., 1996; English et al., 2011; McLean, 2007; O’Brien, 1999; O’Brien, 2001; Reid \& Fielding, 2007; Shattel et al., 2007). Mäori social workers do this in a way that is culturally appropriate. There was also evidence in this research that rangatahi Mäori in particular preferred this approach, as was highlighted by McCutcheon et al (2007).

Mäori knowledge was integrated into the practices of the Mäori social workers at all levels of engagement. From defining boundaries and initial meetings, Mäori models of practice and philosophy guided interactions and decisions made. Time and process is valued and treating others as you would like to be treated. Examples of rapport building provided by these Mäori social workers indicate that they are led by what Ruwhiu (1995) and A. Durie (2001) term a ngäkau Mäori in that they demonstrated the personal qualities of empathy, warmth and compassion and utilised practices that emphasised these, such as touch, awhi, music, waiata, spiritual connection and genuine nurturing. While diverse realities were acknowledged (of both social worker and client), cultural practices were followed through the use of karakia, mihimihi, sharing whakapapa, te reo Mäori and acknowledgement and awareness of wairua. These are supported by the authors Walsh-Tapiata et al. (2006) and Ruwhiu and Ruwhiu (2005). This is not unexpected given that wellbeing for Mäori has strong links to having a positive cultural identity (M. Durie, 2001; Huriwai et al., 2001; Kingi, 2005). 
Reciprocity was seen as the main way to measure whether rapport had been achieved or not. In most cases this was viewed as a celebration of how the relationship had developed, however there was another side to this that was identified. Going beyond their (paid) role and spending extra time with the rangatahi and their whänau, particularly in times of crisis could create difficulties with confidentiality and the blurring of roles between the social workers' employment and community identity. Working longer hours and blurring the boundary lines may increase rapport, but it can have potentially harmful consequences. English et al. (2011, p. 43) found that it is common practice among Mäori SWiS, to go 'the extra mile'. The social worker is sacrificing personal time with his/her own family. Expectations from the rangatahi and the whänau can increase, putting more pressure on the social worker. It can also make it harder for other clinicians (who may be more boundary stringent) to engage with the family. This can become detrimental to the treatment process because access to afterhours teams and access to other clinicians are often necessary. Although this appears to be contradictory to the previous discussion point of being clear about boundaries and role, it is part of the balance between the different themes, for example the utilisation of Mäori values, social work values and being mindful that there are organisational, professional and personal responsibilities too. Even with professional experience a majority of the Mäori social workers interviewed gave examples of times where they were caught out in these kinds of challenging situations.

\section{The need for whänau involvement and that this could improve rapport with rangatahi}

A good relationship with parents and other family members could be seen as detrimental to achieving rapport for a number of reasons. As highlighted by DiGiuseppe et al. (1996), adolescents are often referred by members of their family and may not have the same vested interest in accessing treatment that their family has. The young person may question the trust relationship, for example how much they can say confidentially. However, as one participant pointed out ... they're there 24/7, not us, we're just there for a small chunk. The $\mathrm{MOH}$ and NZGG best practice evidence-based guideline for the assessment and management of children and adolescents (2003) acknowledges the need for whänau involvement and the need to establish relationships with whänau and extended whänau. Whakapapa is a key element in identity and connection for rangatahi Mäori (Biasiny-Tule, 2006). It is a connection to the special people in their life and is respectful to be inclusive of those they are connected to.

\section{Engaging rangatahi as valued members of society, as Mäori, as youth, as taonga.}

A key theme from the research was that Mäori social workers really value rangatahi and their contribution to society. This created an environment of respect and trust where Mäori social workers worked hard to engage with rangatahi from a client-centred perspective as supported by Duncan et al. (2004). This involved being creative with setting/environment and understanding developmental needs and 'youth culture'. Walsh-Tapiata et al. (2006) also accentuated the need for a relationship of trust to be established between adults and youth. McCutcheon et al. (2007) provided tips on how to build rapport with a young person, aligning well with these Mäori social workers who practise in an open and honest way and who use metaphor and humour, although these tend to be driven from a Mäori perspective. It is through engaging rangatahi as valued members of society, as Mäori, as youth and ultimately as taonga, that a rapport relationship can be built. 


\section{Reflective practice is essential}

Reflective practice provided checks and balances for the social worker to reflect on whether their practice was purposeful, safe and effective. Because the ultimate aim is to achieve positive treatment outcomes, each social worker worked towards improving their responsiveness to the needs of the rangatahi and their whänau. The Mäori social workers were not willing to eliminate potential ethical issues by dismissing the elements of their practice that seemed to be contributing to them, they preferred to work through them and utilised cultural and social work supervision to do this. Over time, the Mäori social workers have used action-reflection processes to refine and redefine their practice in order to perform in a way that facilitates rapport with more ease. This shows that Mäori social workers do not go in blind and make it up as they go along. They have clear cultural and social work guidelines that continue to develop through use of action-reflection and experience. Reflective practice is therefore essential in order to inform and re-inform rapport building with rangatahi.

\section{Conclusion}

The aim of this article was to provide insight into how Mäori social workers initiate a unique practice framework to facilitate and maintain rapport building with rangatahi Mäori who access mental health services in the community. They viewed rapport as very important in their practice as it involved engaging the young person and establishing a relationship of trust, genuine commitment and reciprocity. Without rapport access to services and safe and effective treatment is severely compromised. Mäori philosophy, values and practices are integrated into their social work practice. In addition, personal qualities that personified a 'ngäkau Mäori' were identified where the Mäori social workers demonstrated true empathy, passion, warmth and value for the rangatahi and their whänau. The practice implications were discussed and conclusions made around why it is a worthwhile endeavour to have an understanding of Mäori social work perspectives on what informs their practice/s of rapport building with both rangatahi and whänau.

\section{References}

Abell, J., \& Myers, G. (2008). Analysing research interviews. In R. Wodak \& M. Krzyzanowski (Eds.). Qualitative discourse analysis in the social services (pp. 145-161). New York, NY: Palgrave Macmillan.

Antoniou, A. S., \& Blom, T. G. (2006). The five therapeutic relationships. Clinical Case Studies, 5(5), 437-451.

Barbour, R. S. (2008). Introducing qualitative research - A student's guide to the craft of doing qualitative research. London, England: Sage Publications.

Baxter, J. (2008). Mäori mental health needs profile. A review of the evidence: Summary. Palmerston North, New Zealand: Te Rau Matatini.

Beresford, P., Croft, S., \& Adshead, L. (2008). 'We don't see her as a social worker': A service user case study of the importance of the social worker's relationship and humanity. British Journal of Social Work, 38(7), 1388-1407.

Berg, B. L. (2007). Qualitative research methods for the social sciences (6th ed.). Boston, MA: Pearson/Allyn \& Bacon.

Berger, P. L. \& Luckmann, T. (1971). The social construction of reality: A treatise in the sociology of knowledge. Harmondsworth, UK: Penguin Books.

Biasiny-Tule, P. (2006). Rangatahi in the twenty-first century: A new century, a Mäori millennium. In M. Mulholland (Ed.), State of the Mäori nation: Twenty-first-century issues in Aotearoa. Auckland, New Zealand: Reed Publishing (NZ).

Bickman, L., Vidas de Andrade, A. R., Lambert, E. W., Doucette, A., Sapyta, J., \& Boyd, A. S. (2004). Youth therapeutic alliance in intensive treatment settings. The Journal of Behavioral Health Services E Research, 31(2), 134-148.

Bogo, M. (2006). Social work practice: Concepts, processes and interviewing. New York, NY: Columbia University Press.

Braun, V., \& Clarke, V. (2006). Using thematic analysis in psychology. Qualitative Research in Psychology, 3(2), 77-101. 
Cahill, J., Barkham, M., Hardy, G., Gilbody, S., Richards, D., \& Bower, P. (2008). A review and critical appraisal of measures of therapist-patient interactions in mental health settings. Health Technology Assessment, 12(24), 1-18.

Cram, F., Smith, L., \& Johnstone, W. (2003). Mapping the themes of Mäori talk about health. The New Zealand Medical Journal, 116(1170), 1-7.

Cunningham, C. (1998). A framework for addressing Mäori knowledge in research, science and technology. In Te Pümanawa Hauora (Ed.), Te Oru Rangahau: Mäori Research and Development Conference July 1998 (pp. 387-397). Palmerston North, New Zealand: Te Pütahi ä Toi, Massey University.

Denscombe, M. (1998). The good research guide for small-scale social research projects. Buckingham, England: Open University Press.

DiGiuseppe, R., Linscott, J., \& Jilton, R. (1996). Developing the therapeutic alliance in child-adolescent psychotherapy. Applied E Preventative Psychology, 5, 85-100.

Duncan, B. L., Miller, S. D., \& Sparks, J. A. (2004). The heroic client: A revolutionary way to improve effectiveness through client-directed, outcome-informed therapy. (Rev. ed.). San Francisco, CA: Jossey-Bass.

Durie, A. E. (2001). Te rërenga o te rä: Autonomy and identity: Mäori educational aspirations. Unpublished doctoral dissertation, Massey University, Palmerston North, New Zealand.

Durie, M. H. (2001). Mauri ora - The dynamics of Mäori health. Auckland, New Zealand: Oxford University Press.

English, A., Selby, R., \& Bell, H. (2011). Working with whänau: Mäori social work in schools. Otaki, New Zealand: Te Wananga o Raukawa.

Garcia, J. A., \& Weisz, J. R. (2002). When youth mental health care stops: Therapeutic relationship problems and other reasons for ending youth inpatient treatment. Journal of Consulting and Clinical Psychology, 70(2), 439-443.

Hawley, K., \& Weisz, J. (2005). Youth versus parent working alliance in usual clinical care: Distinctive associations with retention, satisfaction, and treatment outcome. Journal of Clinical Child and Adolescent Psychology, 34(1), 117-128.

Hirini, P. (1997). Counselling Mäori clients: He Whakawhiti Nga Whakaaro i te Tangata Whaiora Mäori. New Zealand Journal of Psychology, 26(2), 13-18.

Howgego, I. M., Yellowlees, P., Owen, C., Meldrum, L., \& Dark, F. (2003). The therapeutic alliance: The key to effective patient outcome? A descriptive review of the evidence in community mental health case management. Australian and New Zealand Journal of Psychiatry, 37(2), 169-183.

Huriwai, T., Robertson, P. J., Armstrong, D., Kingi, T., \& Huata, P. (2001). Whanaungatanga - A process in the treatment of Mäori with alcohol - and drug-use related problems. Substance Use E Misuse, 36(8), 1033-1051.

Jonson, H., Su'a, T., \& Crichton-Hill, Y. (1997). Biculturalism and counselling across cultures. In R. Manthei (Ed.), Counselling - The skills of finding solutions to problems, pp. 18-35. Auckland, New Zealand: Addison Wesley Longman.

Keen, M. (2005). Integrated practice in mental health social work. In M. Nash, R. Munford \& K. O’Donoghue (Eds.), Social work theories in action (pp. 80-92). London, England: Jessica Kingsley Publishers.

Kingi, T. (2005). Mäori mental health: Past trends, current issues, Mäori responsiveness. Auckland, North Shore, Albany, New Zealand: Te Mata o te Tau Academy for Mäori Research and Scholarship.

Maidment, J. (2006). The quiet remedy: A dialogue on reshaping professional relationships. Families in Society: The Journal of Contemporary Social Services, 87(1), 115-121.

McCutcheon, L. K., Chanen, A. M., Fraser, R. J., Drew, L., \& Brewer, W. (2007). What every clinician wants to know ... Tips and techniques for engaging and managing the reluctant, resistant or hostile young person. The Medical Journal of Australia, 187(7), 64-67.

McLean, J. M. (2007). Pushing the boundaries: Relationships with adolescents. Unpublished master's thesis, Victoria University, Wellington, New Zealand.

Mead, L. T. (1996). Ngä aho o te kakahu matauranga: The multiple layers of struggle by Mäori in education. Unpublished doctoral dissertation, University of Auckland, Auckland, New Zealand.

Ministry of Health \& New Zealand Guidelines Group. (2003). The assessment and management of people at risk of suicide. Wellington, New Zealand: Ministry of Health, New Zealand Guidelines Group.

Nafisi, N., \& Stanley, B. (2007). Developing and maintaining the therapeutic alliance with self-injuring patients. Journal of Clinical Psychology: In Session, 63(11), 1069-1079.

Nash, M., Munford, R., \& O’Donoghue, K. (2005). Introduction: Integrating theory and practice. In M. Nash, R. Munford \& K. O’Donoghue (Eds.), Social work theories in action (pp. 15-28). London, England: Jessica Kingsley Publishers.

Norfolk, T., Birdi, K., \& Walsh, D. (2007). The role of empathy in establishing rapport in the consultation: A new model. Medical Education, 41(7), 690-697.

O'Brien, A. J. (1999). Negotiating the relationship: Mental health nurses' perceptions of their practice. Australian and New Zealand Journal of Mental Health Nursing, 8(4), 153-161.

O'Brien, L. (2001). The relationship between community psychiatric nurses and clients with severe and persistent mental illness: The client's experience. Australian and New Zealand Journal of Mental Health Nursing, 10(3), 176186.

Okamoto, S. K. (2003). The function of professional boundaries in the therapeutic relationship between male practitioners and female youth clients. Child and Adolescent Social Work Journal, 20(4), 303-313.

O'Leary, Z. (2004). The essential guide to doing research. London, England: Sage Publications. 
Reid, H. L., \& Fielding, A. J. (2007). Providing support to young people: A guide to interviewing in helping relationships. New York, NY: Routledge.

Ruwhiu, L. A. (1995). Home fires burn so brightly with theoretical flames. Te Komako VII(1), 21-24.

Ruwhiu, L. A. (2001). Bicultural issues in Aotearoa New Zealand social work. In M. Connolly (Ed.), New Zealand social work: Contexts and practice (pp. 54-71). Auckland, New Zealand: Oxford University Press.

Ruwhiu, P. T., \& Ruwhiu, L. A. (2005). Ko te pae o te atua mai i nga whakaaro hohonu nei, hei oranga mo te ira tangata. Te Komako 17(2), 4-19.

Shattell, M. M., Starr, S. S., \& Thomas, S. P. (2007). 'Take my hand, help me out': Mental health service recipients' experience of the therapeutic relationship. International Journal of Mental Health Nursing, 16(4), 274-284.

Statistics New Zealand. (2010). Demographic trends: 2010. Retrieved from http://www.stats.govt.nz/browse_for_ stats/population/estimates_and_projections/demographic-trends-2010/chapter1.aspx.

Sterlin, R. (2006). Where relational theory and attachment theory intersect: A real relationship and a real attachment. Clinical Social Work Journal, 34(2), 161-174.

Thomas, G. (2007). The power of the therapeutic relationship: Bringing balance to evidence-based practice. Social Work Review, XIX(4), 55-66.

Walsh-Tapiata, W., Metuamate, A., Rikihana, T., Webster, J., Warren, T., \& Kiriona, D. (2006). Mäori youth (rangatahi) lead positive social change in identifying health issues. Commonwealth Youth and Development Journal, $4(1), 2-16$.

Ware, N., Tugenberg, T., \& Dickey, B. (2004). Practitioner relationships and quality of care for low-income persons with serious mental illness, Psychiatric Services, 55(5), 555-559. 